\title{
Analysis of the EPB-TBM Excavation Parameters Used in a Tunnel Construction in Istanbul
}

\author{
Omur Acaroglu Ergun, Cemalettin Erdoğan, Emre Ekinci \\ Istanbul Technical University, Faculty of Mines, Mining Engineering Department \\ Mining Engineering Department, Istanbul Technical University, 34469 Maslak, Istanbul, Turkey \\ acaroglu@itu.edu.tr; erdogance@itu.edu.tr; emreleo@gmail.com
}

\begin{abstract}
Mechanical excavation methods have become widespread in the world and our country and importance of the selection of proper machine is getting increase for achieving efficient excavation. In this study, the excavation parameters of an EPB-TBM machine used in tunnel project which is purpose of collecting the waste water from Eyüp to Yenikap1 in the ISKI Yenikap1 Waste Water Plant were analyzed. During the machine passing under a river bed in the Güngören formation, seven ground samples were collected and sieve analyses were made. The ground of continuing, particle size distribution and ground conditioning type were examined by using sieve analysis. After the Güngören formation EPB-TBM was entered in the Trakya Formation and started excavation fractured and jointed claystone. During the excavation in this relatively harder formation, the machine was transformed from EPB to TBM mode, and then some of the wedge cutters were placed with disc cutters for increasing the efficiency of the excavation. During this period, analysis of the excavation parameters were made using the torque, thrust force and those penetration indexes, advance and penetration values rate. This study shows that data obtained from machine gives useful information about formation passing.
\end{abstract}

Keywords: Earth Pressure Balance (EPB) Type Tunnel Boring Machine (TBM), performance parameters, thrust force, torque, excavation rate.

\section{Introduction}

In today's world, hundreds of kilometres of galleries/tunnels are being constructed. Since high rates of urbanization and demand of infrastructure has also increased, tunnels need to be excavated in the quickest and safest way. Moreover, the mining activities will be operated near the urban areas and because of this, the contractors tend to choose the underground mining methods to avoid causing environmental impact. Especially, Tunnel Boring Machine (TBM) is an economic machine for excavating long tunnels in suitable formations. TBM can excavate approximately 2-4 times faster than drilling and blasting method [1-2]. Beside TBM has high initial investment costs, excavation with TBM has some advantages such as ability of preventing subsidence, low vibration and sound levels in excavation thus TBM has become popular in excavation projects [3-4].

Although, the basic excavation principles in tunnel boring machines are the same, the cutter head designs and the types of cutters, supporting systems, the transportation of the muck can be different in TBMs related to geological formation [3]. The selection of TBM is a fundamental issue for excavating tunnels in most economical and the fastest way. Thus, performance prediction of TBM which is a factor in selection of TBM, is an important issue for acquiring optimum cost in excavation projects.

In this paper, the excavation parameters of Earth Pressure Balance (EPB) which is a type tunnel boring machine is analysed in the Second Region Waste Water Tunnels Construction of European Side of Istanbul.

\section{Earth Pressure Balance (EPB) Type Tunnel Boring Machine}

The Earth Pressure Balance (EPB) Type TBM is used for softer fairly cohesive soils to avoid ground settlements in these formation. The first modern EPB was manufactured in Japan in 60's. Japanese had been manufactured hundreds of EPB between 60's-80's [3,5]. Today EPB is one of the main alternative machinery in soft ground excavation.

The basic excavation principle of the EPB is allow the pressure in the cutter head and face cavity to build up naturally by the pressure of the ground itself and the accompanying ground water. Thus, excavated material can be used for supporting the excavation [6]. It is an important issue that supporting pressure should be adjusted to compensate the ground pressure. 
EPB machines are not affective in soils having fine material less than $\% 10$ and water heads over 4 bar [7]. With foam additive, the formation can be conditioned for EPB's optimum excavation [8]. The finest working condition of EPB machines is the humidity level of the ground is \%15-10 and below. EPB machine can overcome 10 bar face pressures [9]. These machines can be also used in hard rock conditions with suitable cutter head design and muck transportation units. A schematic view of EPB machine is given in Figure 1.

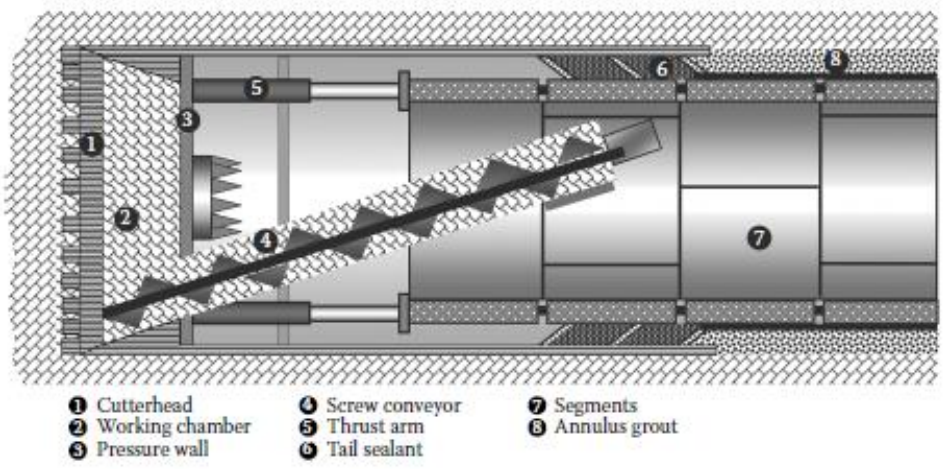

Fig. 1: Schematic of an EPB TBM [7].

The cutterhead is rotated and the thrust arm is generating a thrust force for supporting the face. Thus, the working chamber is filled with excavated material. When the working chamber is full, excavated material has been transported by screw conveyor. The screw conveyor is used for reducing the face pressure to the normal levels and transporting the excavated material steadily $[3,6,10]$. The segments are mounted while excavation is in progress. The over excavated surfaces are filled with annulus grout then tail sealant is applied for forming a barrier between the tail shield and concrete segments to effectively seal off any ingress of water and backfill grout back into tail end of the machine.

There are different working modes in EPB machines which are given in Figure 2. The working modes can be selected regarding the formation. In self-supporting low permeable stable soils and hard rock conditions without water income, they can be used in one open mode without giving face pressure. In self-supporting stable soils with the moderate water income, they can be used in transition mode, being half-filled with conditioned muck without giving any face pressure, and may be giving pressure only by compressed air to stop water ingress [11].

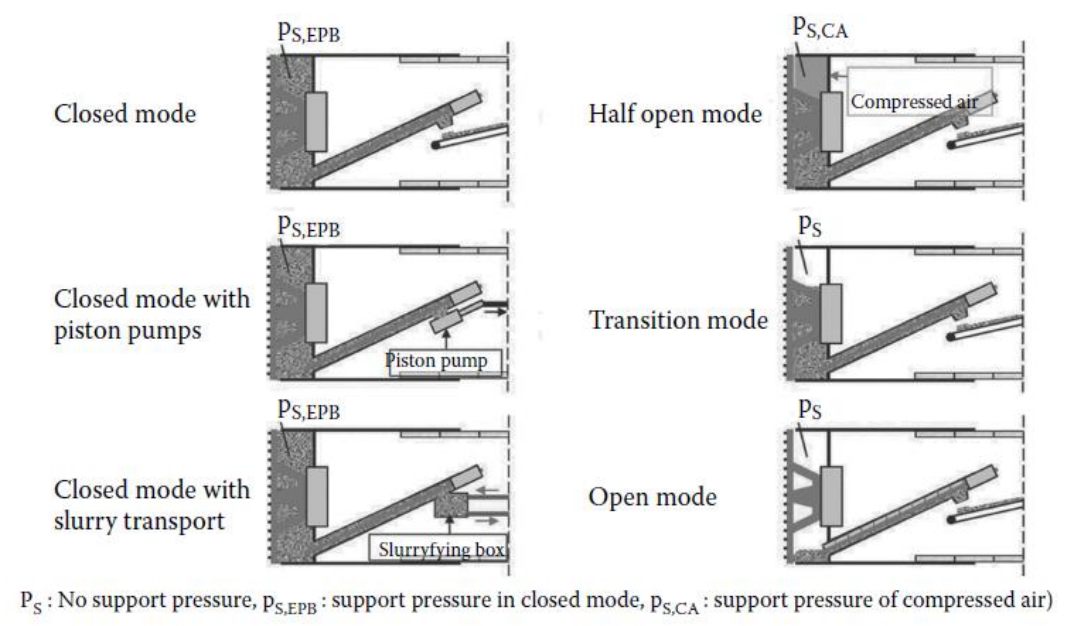

Fig. 2: Working modes of EPB [9].

There are some important issues when the excavation principles of EPB are considered. Firstly, theoretical support pressure should be estimated firmly with consideration water pressure and ground pressure of the face for designing support, cutterhead and selection of suitable haulage system. Moreover, operation parameters should be adjusted for continuing 
excavation operations safely. For example, the thrust force should not overcome face pressure for avoiding the subsidence. Conditioning agent should be injected directly to the face. If the screw conveyor is wear out rapidly and excavation amount is below the demand, conditioning agent may be injected from screw conveyor. The average excavated material size should be estimated for selecting the suitable haulage system and controlling the flow of excavated material from working chamber. It is also important factor that prevent water flow from the face. The excavation performance of EPB machine is directly affected by these factors.

\section{The Second Region Waste Water Tunnels Construction of European Side of Istanbul}

The project is construction of the Second Region Waste Water Tunnels Construction of European Side of Istanbul by İlci-Özgün Joint Venture which is the controlled by Directorate of Istanbul Water and Sewerage Administration. The waste water of Eyüp, Alibeyköy, Fatih and Golden Horn region is collected and transferred to Yenikapı Purification Plant with this project. The purified waste water will be pumped to 300 meters offshore of Marmara Sea. The tunnel length is 9350 meter with 3,60 meter diameter that the route of the tunnel is given in Figure 3.

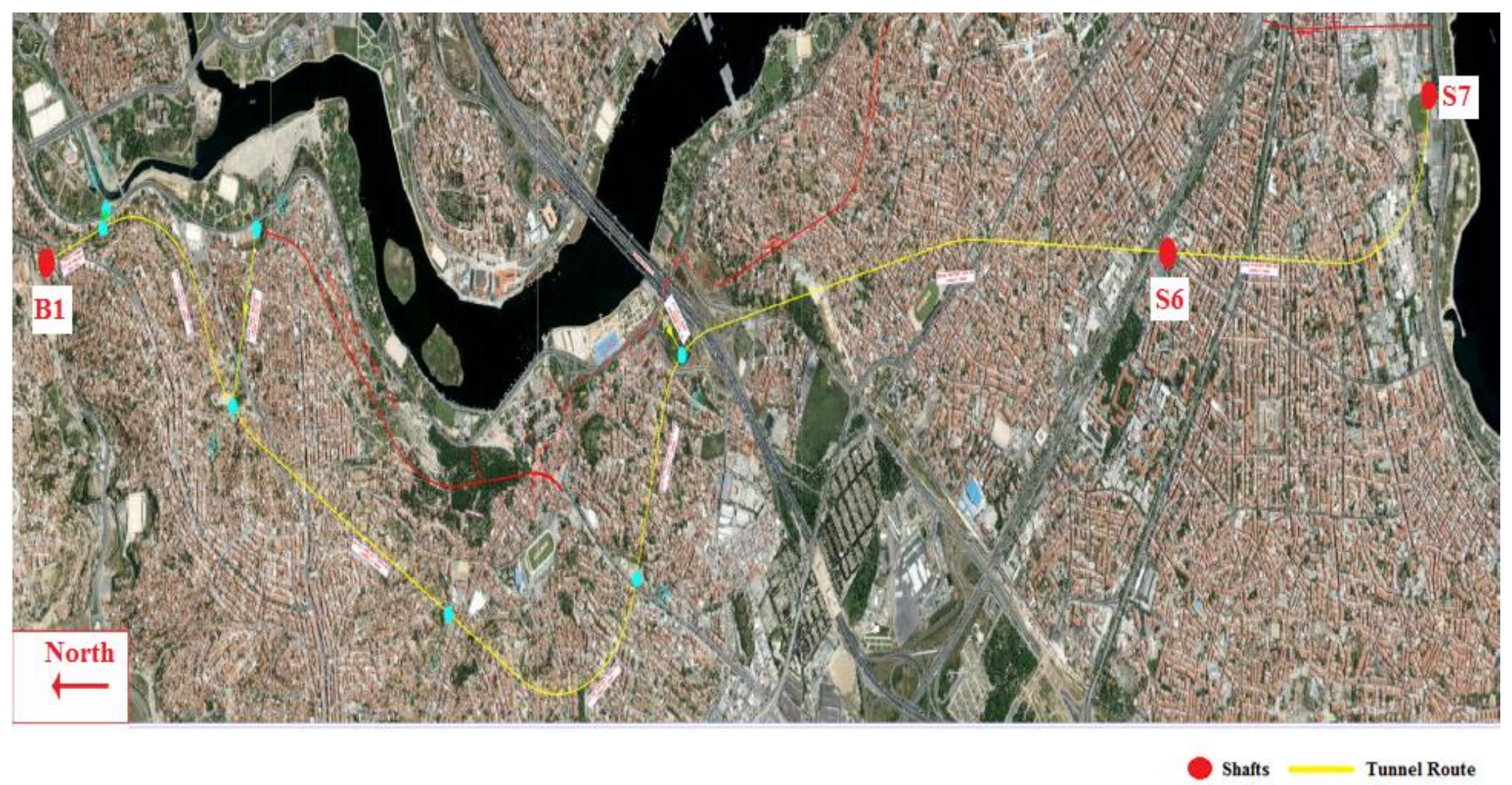

Fig. 3 : Route of the tunnel.

\subsection{Geology Of The Project}

21 boreholes in the depth ranging from 15,21 meter to 87 meter was drilled in 844.20 meter in total to estimate the geological and geotechnical properties of the formation in the tunnel route. The stratigraphy of north of the tunnel route is based on "Trakya Formation". Trakya Formation consists predominantly of an alternation of sandstone, siltstone and shale; in its lower parts there are limestone horizons of various thicknesses and in its middle and upper parts conglomerate and sandstone lenses.

In south route of tunnel geological formation is "Güngören Formation". This formation are based on yellowish browngreen clay, white marn and between them irregular limestone layer. The clay is thin layered which includes the sandstone lenses. Near the surface, clay is brown since it is includes organic materials. In north of the tunnel route near Eyüp region, the formation is different from these formations. The formation of this region consists gravel included sand and gray-black clay and mud which is named as "Kuşdili Formation" [12]. 


\subsection{The EPB Used in the Project}

M-1070 model EPB type TBM which is manufactured by Herrenknecht was used in the project. The figure of TBM is given in Figure 4 [13].

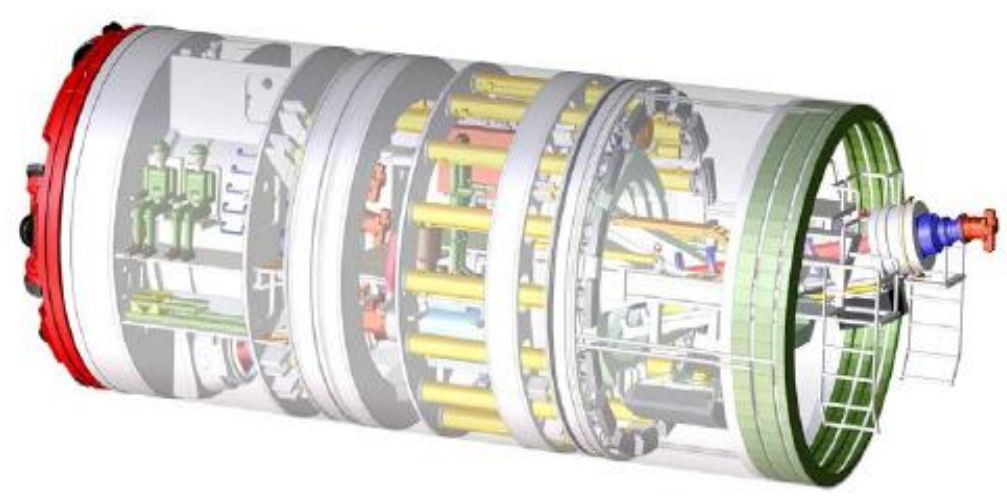

Fig. 4: Herrenknecht M-1070 EPB-TBM [13].

The cutterhead diameter of the machine is $4560 \mathrm{~mm}$ and weight is $34800 \mathrm{~kg}$. Cutter head is rotated by $2 \mathrm{x} 400 \mathrm{~kW}$ electric motors wich provide $2307 \mathrm{kNm}$ for $2.75 \mathrm{rpm}$. 16 thrust arm are included which can apply $16625 \mathrm{kN}$ thrust force. Rottaion cutter head can be changed between 2,75-7,22. The length of screw conveyor is 12,3 meter which can rotate $22 \mathrm{rpm}$ when it is full with material.

\section{Analysis of performance parameters of EPB used in the project}

The analysis of the EPB excavation parameters was conducted between October-December 2010. 7 samples were collected from 1461, 1481, 1520, 1560, 1584, 1616, 1697 rings and then samples were analysed in wet sieve [14]. EPB was excavated alluvial material in this time period. The data of thrust force, torque, penetration index value of these force values and excavation rates in these rings were also obtained and analysed with the material samples collected.

\subsection{Sieve Analyses}

The wet sieve analysis was performed starting from $64 \mathrm{~mm}$ to $38 \mu$ in Istanbul Technical University Mineral at the Mineral Processing Plot Plant.

Oversize and undersize samples were dried and scaled their weight without huminity. The samples were collected from 1753,2 $\mathrm{m}$ and 2036,4 $\mathrm{m}$ (between 1461 and 1697 rings) of the construction and this route came to across a stream bed. The formation consists sand, yellow sandstone, clay and schist. In addition to these, there is a strong water income in this formation. These informations are also seen in sieve analyses which 1584 ring analysis is given in Figure 5.

According to analyses, the soil conditioning should have applied for reducing the permeability and acquiring penetration. The contractor also firm applied an agent mixture of \% 0,2-2 polymer and \%2-5 foam in accordance with water income to the working chamber.

The ground pressure values of the route was also collected that is given in Figure 6. The ground pressure was increased to 1-1,3 bar in the steam bed zone then it was decreased 0,25-0,50 bar in harder formation. In this steam bed zone, the lower pressure values in 1461 and 1481 ring was estimated since a hard sandstone lense is included.

\subsection{Torque Analyses}

The torque values that was collected and there are 2 different region in the Figure 7 . The machine was operated as EPB mode in Region I. In Region II, the machine was operated as TBM mode. The torque values had a range from 1200 $\mathrm{kNm}$ to $1700 \mathrm{kNm}$ in EPB mode. This value decreased 700 to $1300 \mathrm{kNm}$ in TBM mode.

Penetration index related to torque values (PIT) which is referred as torque requirement for $1 \mathrm{~mm}$ penetration, is obtained ratio between torque value and penetration value for one rotation of the cutting head. PIT were divided in 3 region for commenting the values correctly. This graph is given in Figure 8 showing Region I and Region II where samples collected. PIT values were expected to show similarity with sieve analyses. As it is seen in Figure 7, the values are far 
different in Region I and Region II. PIT values in Region I are approximately 4-5 times bigger than PIT values in Region II. This issue can be explained with the existence of sandstone lenses in soft ground in 1461, 14811520 Ring. The reason of increment of PIT values in Region III is changing of the formation where is Trakya Formation including clastone. Because of the formation, PIT values are up to $100-150 \mathrm{kNm} / \mathrm{mm}$, so cutters were changed from chisel bit to disc cutters and machine was transferred to TBM mode.

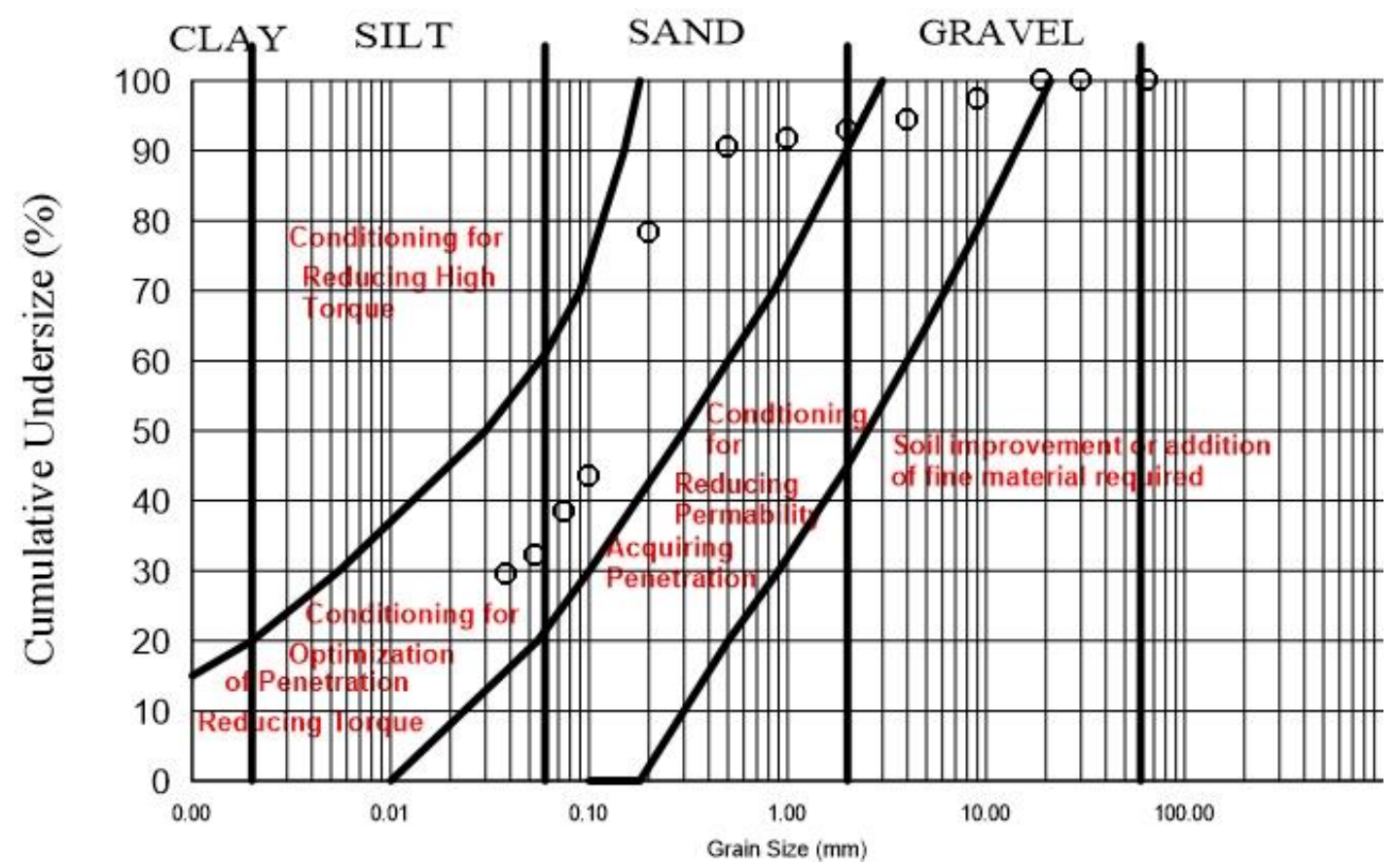

Fig. 5: Cumulative undersize graph in 1584 ring.

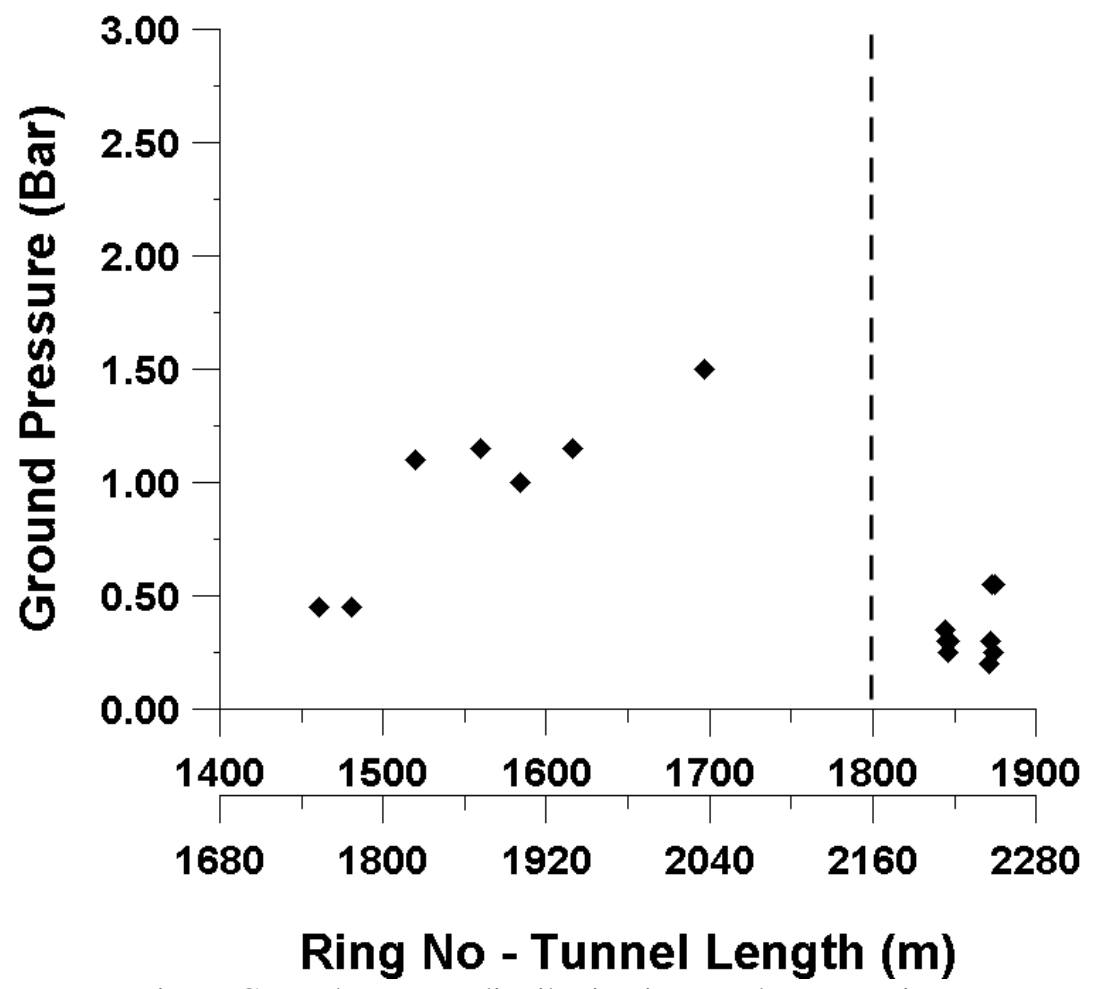

Fig. 6: Ground pressure distribution in tunnel construction. 

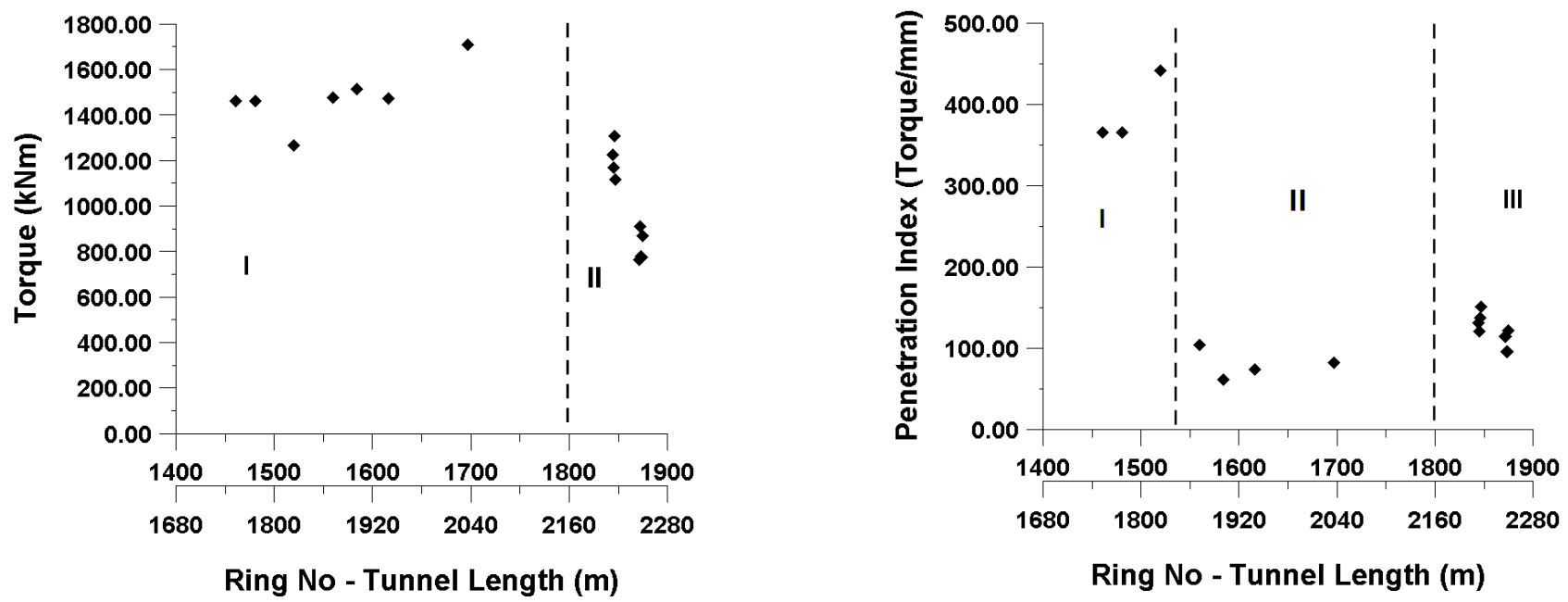

Fig. 7: Torque distribution in tunnel and penetration related torque index values.

\subsection{Thrust Force Analysis}

Thrust force values in Region I is higher than Region II which is given in Figure 8. Penetration index related to thrust values (PITH) which is referred as thrust force requirement for $1 \mathrm{~mm}$ penetration, is obtained ratio between thrust force value and penetration value for one rotation of the cutting head. The main reason of the higher values of PITH in the Region I is the existence of sandstone lense in this formation as seen from Figure 8. After passing the Trakya formation in region III, PITH values did not change in spite of being harder formation, since chisel cutters were changed with disc cutter.

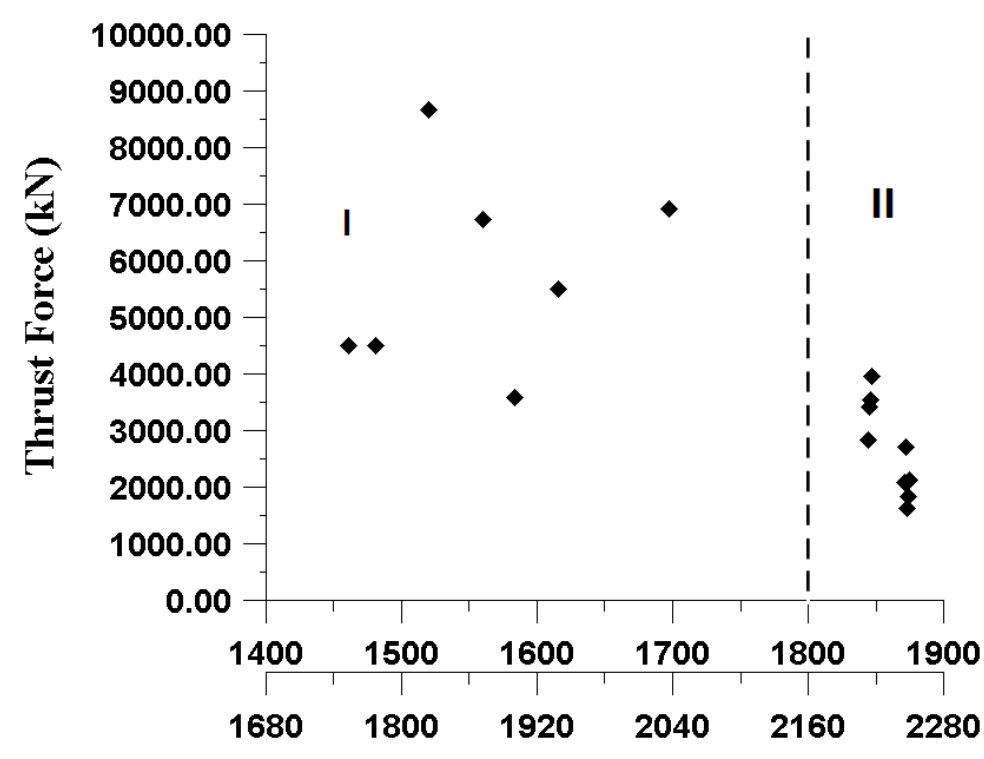

Ring No - Tunnel Length (m)

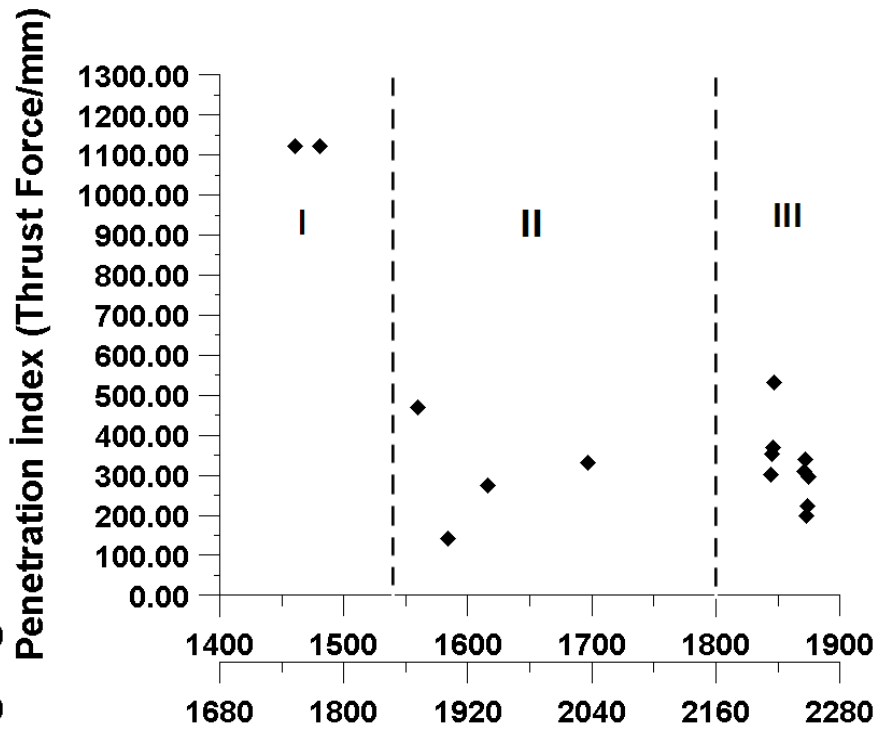

Ring No - Tunnel Length (m)

Fig. 8: Thrust force distribution in tunnel and penetration related torque index values.

\subsection{Rotation and Excavation Rate}

The rotation per minute (rpm) is stable in 2,5 between 1461-1697 rings. Then the rpm is increased to 3-4,5 rpm since the machine was excavated in "Trakya Formation". The excavation rate $(\mathrm{mm} / \mathrm{min})$ was also observed which is given in Figure 9. The excavation rate in Region I was low since the existence of sandstone lenses in this region. In Region III, the machine was excavated faster than Region I but slower than Region II. These figures also shows effects of formations and using different cutters on the excavation. 

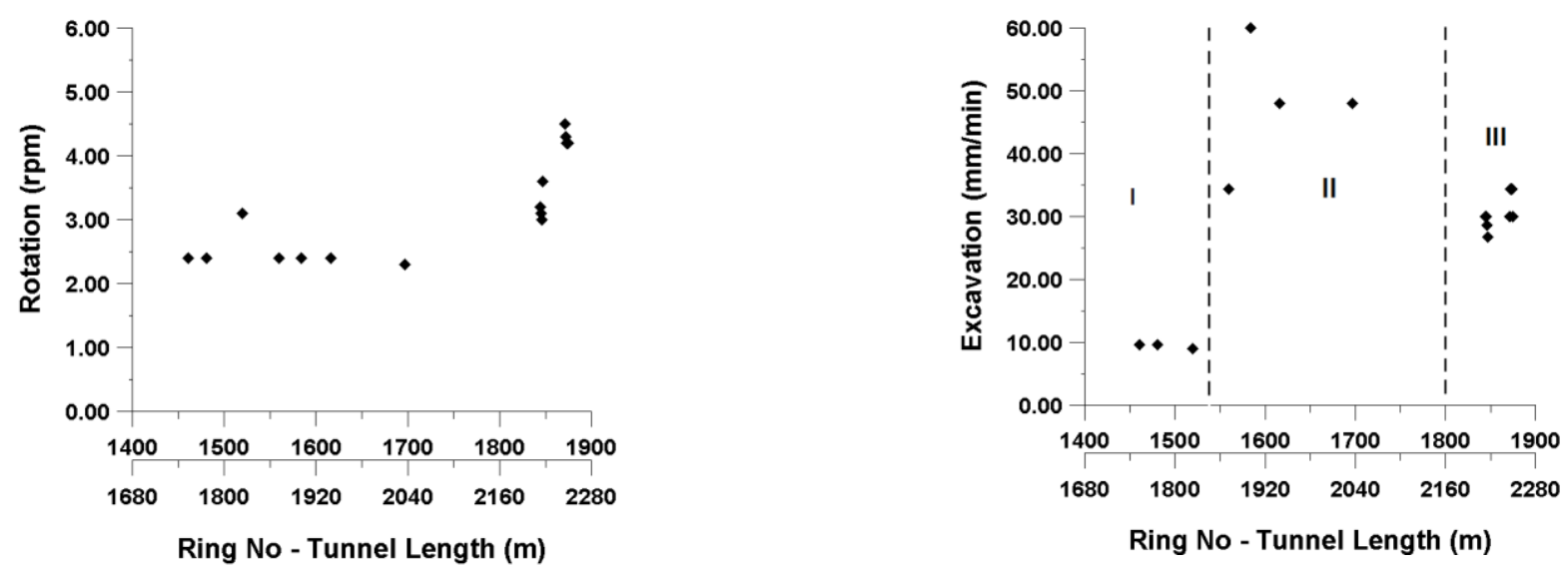

Fig. 9: Rotation and excavation rate distribution in tunnel.

\section{Conclusion}

In this study, analysis of the EPB type TBM excavation parameters used in the second region waste water Tunnels construction of european side of Istanbul was conducted between October-December 2010.

In this time period, excavation was operated in a steam bed zone. Samples were collected and applied sieve analyses. According to the analyses, soil conditioning was required for increasing penetration and reducing the permability and torque. The contractor firm also applied an agent mixture of \%0,2-2 polymer and \%2-5 foam in accordance with water income to the working chamber to overcome these problems. After 1800 Rings $(2160 \mathrm{~m})$, the formation became Trakya formation. Due to this, machine was transformed to TBM and chisel cutters were changed to disc cutters.

Excavation parameters were evaluated according to torque, thrust force and their penetration index values, excavation rate and rotation of per minute. Penetration index values related to torque and thrust force were calculated. According to penetration index values, the formation which the machine excavated, has a direct effect to machine performance. For example, the sand stone lenses was occured discrement in excevation rate in Region I. Despite the hard formation existence in Region III, the excavation rate was not low as excavation rate in Region I since the cutting tools were changed to disc cutters.

To conclude up, this study has showed that the formations have a direct effect on machine performance parameters. The excavation parameters such as torque, thrust force and their penetration index values and excavation rate must be analysed for evaluating the formation excavability and observing the machine working situation.

\section{Acknowledgements}

We are very grateful to Ilci-Ozgun Joint Venture for providing working environment and their interest for collecting samples and datas.

\section{References}

[1] S. Kahraman, "Historical Evaluation of Full Face Tunnel Boring Machines (TBMs)," in Proceedings of the 2nd Symposium on Underground Excavations for Transportation, İstanbul, Turkey, 2007, pp. 57-62 (in Turkish).

[2] N. Barton, "TBM performance estimation in rock using QTBM," Tunnels and Tunnelling International, vol. 31, pp. 3034, 1999.

[3] H. Tunçdemir, "Ground characteristics effecting the excavation performance of full face EPB machines and an example, İzmir metro tunnel," in Proceedings of the $4^{\text {th }}$ National Rock Mechanics Symposium, Zonguldak, Turkey, 1998, pp. 159173 (in Turkish).

[4] O. Acaroglu and O. Bayram, "Analysis of the EPB Excavation Parameters Used in Kadıköy-Kozyatağ 1 Metro Tunnel Excavations," in The 22nd International Mining Congress of Turkey, Ankara, Turkey 11-13 May, 2011 (in Turkish).

[5] B. Maidl, M. Herrenknecht, and L. Anheuser, Mechanised Shield Tunnelling. Berlin, Ernst und Sohn, 1996.

[6] R. T. Tatiya, Surface and Underground Excavations Methods, Techniques and Equipment. Netherlands: CRC Press/Balkema, 2013. 
[7] V. Guglielmetti, P. Grasso, A. Mahtap, and S. Xu, Mechanized Tunnelling in Urban Areas: Design Methodology and Construction Control. Boca Raton, FL: Taylor \& Francis, 2008.

[8] Efnarc, Specification and guidelines for the use of specialist products for mechanized tunnelling (TBM) in soft ground and hard rock. European Federation Dedicated to Specialist Construction Chemicals and Concrete Systems, 2005.

[9] M. Herrenknecht, M. Thewes, and C. Budach, "The development of earth pressure shields: From the beginning to the present," Geomechanics and Tunnelling, vol. 4, no. 1, pp. 11-35, 2011.

[10] L. Ozdemir, "Mechanical Excavation Techniques in Underground Construction," Short Course Notebook, vol. 1, pp. 427, 1992.

[11] J. B. O'Carroll, A Guide to Planning Constructing and Supervising Earth Pressure Balance TBM Tunneling. Parsons Brinckerhoff, 2005.

[12] F. Y. Oktay and O. M. İlkışı, ISSKİ South Goldenhorn II Sewage Tunnel Geologic/Geotechnical Survey Report, Anadolu Yerbilimleri, no. 766-I, 2009 (in Turkish).

[13] A. G. Herrenknecht, Operating Manuel M-1070 EPB400AH Tunnelling Equipment. 2006.

[14] O. Acaroglu and E. Ekinci, "Analysis of the EPB-TBM Excavation Parameters Used in the Second Region Waste Water Tunnels Construction of European Side of Istanbul," in Proceeding of the $23^{\text {rd }}$ International Mining Congress of Turkey, pp. 1313-1323, Antalya, Turkey, 2013 (in Turkish). 